\author{
Quality of investments in rainwater harvesting systems: Particles Swarm \\ Optimization for maximization of net present value
}

\author{
Marina Sangoi de Oliveira Ilha', Marcus André Siqueira Campos²
}

\begin{abstract}
RESUMO
A análise da qualidade dos investimentos deve fazer parte da tomada de decisão pela implantação dos sistemas de aproveitamento de água pluvial, de modo a avaliar se os investimentos na redução dos impactos ambientais são atrativos também sob o ponto de vista dos investidores. Considerando-se os métodos baseados no fluxo de caixa descontado, o valor presente líquido é o melhor indicador para tal avaliação, pois permite decidir qual é o melhor entre dois projetos excludentes, além de apresentar uma rotina de cálculo simples e de fácil entendimento pelos usuários. Este trabalho teve como objetivo propor uma ferramenta para a análise da qualidade dos investimentos em um sistema de aproveitamento de água pluvial, baseada na otimização do valor presente líquido, por meio da técnica de Particles Swarm Optimization. Para demonstrar a utilização da ferramenta proposta, desenvolveu-se um estudo de caso para uma edificação pública existente. Foram considerados três cenários para a tarifa água: sem reajuste e com valores limite e máximo do reajuste histórico das tarifas da concessionária local: 5,69 e 19,63\% ao ano. Em todos os cenários foram encontradas duas alternativas: existência de cobrança da tarifa de esgoto correspondente ao volume de água pluvial utilizado e inexistência dela. Os resultados obtidos com o uso da ferramenta proposta podem auxiliar na tomada de decisão para uso dos sistemas de aproveitamento da água pluvial. Palavras-chave: sistemas prediais; particles swarm optimization; qualidade de investimentos; aproveitamento de água pluvial.
\end{abstract}

\begin{abstract}
Analysis of the quality of investments should be part of decision-making for implementing rainwater-harvesting systems in order to evaluate whether investments in environmental impacts mitigation are also attractive from the point of view of investors. Considering discounted cash flow methods, net present value is the best indicator for this analysis, because it allows deciding which is the best between two mutually exclusive projects, and it also presents a simple calculation routine and is easily understood by users. This work aimed at presenting a decision-making analysis tool for rainwater-harvesting systems, which is based on the maximization of net present value, using the Particles Swarm Optimization technique. The decision tool was used to evaluate the quality of the investments for implementing a rainwater-harvesting system, considering a building of the public tax category. Three scenarios of the water bill were considered: current rate structure and increases of 100\%, 150\% and 200\%. All scenarios contemplate two alternatives: with sewage rate corresponding to the rainwater use and no fee. Results illustrate opportunities for investments in rainwater-harvesting systems.
\end{abstract}

Keywords: plumbing systems; particle swarm optimization; quality of the investments in rainwater harvesting.

de abastecimento, em atividades que prescindem de um insumo com esta qualidade.

Inseridos nesse contexto, os sistemas de aproveitamento de água pluvial vêm sendo incorporados às edificações mais sustentáveis, de forma a empregar "água menos nobre para fins menos nobres" e, com

'Doutora, Livre-Docente do Departamento de Arquitetura e Construção da Faculdade de Engenharia Civil, Arquitetura e Urbanismo da Universidade Estadual de Campinas (Unicamp) - Campinas (SP), Brasil.

${ }^{2}$ Doutor, Professor Adjunto da Universidade Federal de Goiás - Goiânia (GO), Brasil.

Endereço para correspondência: Marina Sangoi de Oliveira Illha - Rua Saturnino de Brito, 224 - Cidade Universitária - 13083-889 - Campinas (SP), Brasil - E-mail: millha@fec.unicamp.br Recebido: 14/05/12 - Aceito: 17/04/14 - Reg. ABES: 379 
isso, reduzir o consumo total de água potável (AMORIM \& PEREIRA, 2008; CAMPOS, 2004; LIMA et al., 2011; MAY, 2004).

Vários são os aspectos a serem considerados no desempenho dos sistemas de aproveitamento de água pluvial, dentre os quais destacam-se: métodos mais adequados para o dimensionamento dos reservatórios; volume ocioso/faltante em função do regime de chuvas; qualidade da água nos diferentes pontos do sistema, incluindo o volume inicial a ser descartado. Além disso, a análise da qualidade dos investimentos necessários deve ser incorporada à tomada de decisão pela implantação de tais sistemas, de modo a avaliar se os investimentos na redução dos impactos ambientais são atrativos também sob o ponto de vista dos investidores, por meio de um equilíbrio entre aqueles necessários e os retornos econômicos mensais advindos da implantação desses sistemas. Segundo Lima Jr. et al. (2011, p. 40), esta avaliação

deve conter informações na forma de indicadores da capacidade de fazer, dos resultados esperados, da segurança e dos riscos do investimento no empreendimento, que deem sustentação às avaliações do empreendedor destinadas a validar a oportunidade de investimento sob crítica.

O período de retorno dos investimentos (payback atualizado) foi, por muito tempo, essencialmente o único indicador econômico considerado nessas análises, quando da implantação dos primeiros programas de conservação de água consolidados no Brasil (YWASHIMA, 2005). Contudo, este indicador não é o mais adequado para esta avaliação, pois não permite mensurar a real capacidade no momento do investimento, além de não possibilitar comparações entre diferentes soluções (MONTEIRO, 2003; LIMA JR., 1998).

Por sua vez, o valor presente líquido (VPL) permite quantificar a real vantagem econômica do investimento, além de ser útil em um processo para classificar alternativas que são excludentes entre si. Assim, trata-se de um indicador mais adequado à avaliação do problema em questão. A maximização do VPL tem sido objeto de diferentes estudos relacionados com a programação das atividades a serem realizadas ao longo de um projeto, merecendo destaque o emprego de algoritmos genéticos para este fim (VANHOUCKE, 2009; ZHANG \& WANG, 2008). A Particle Swarm Optimization (PSO) consiste em outra forma de abordagem para a otimização dos problemas que, de maneira similar aos algoritmos genéticos, parte de soluções iniciais e, por meio de iterações, determina a melhor solução para o problema em questão (ZHANG \& WANG, 2008).

Além das vantagens dos algoritmos genéticos, a PSO é de fácil implementação e apresenta desempenho efetivo na solução dos problemas de otimização. Esta técnica também apresenta grande flexibilidade, que se traduz na possibilidade de incorporar futuramente outras variáveis na solução do problema a ser otimizado, além de demonstrar rápida convergência.
Nesse contexto, este trabalho teve como objetivo expor uma ferramenta para a análise da qualidade dos investimentos em sistemas prediais de aproveitamento de água pluvial, baseada na otimização do VPL do investimento por meio da técnica de PSO.

\section{PARTICLE SWARM OPTIMIZATION}

A PSO é uma técnica de otimização estocástica de funções não lineares, baseada em populações, e é inspirada no comportamento social das aves (BOERINGER \& WERNER, 2004).

Tal algoritmo em muito se assemelha com os evolucionários, tais como os genéticos, que consistem em uma simulação na qual o melhor “sobrevive", seguindo a Teoria de Darwin. Porém, a técnica PSO requer menos conhecimento computacional e um número menor de linhas de programação, resultando em menor tempo para obtenção do valor ótimo (ENGELBRECHT, 2007).

A busca por alimentos e/ou um lugar para o ninho e as iterações entre os pássaros são otimizados, tais como em um mecanismo de otimização dos problemas. Ao comparar um indivíduo com os pássaros, a área sobrevoada seria o espaço para a busca deste algoritmo e o "encontrar alimento" corresponderia a encontrar o ponto ótimo da função objetivo (CANÔAS, 2008).

O processo de otimização se inicia com a seleção das variáveis e as restrições existentes e, por meio do espaço de busca, verifica-se qual é o ponto ótimo da função objetivo do problema em questão.

As possíveis soluções, chamadas de partículas, "voam” no espaço da situação, seguindo as partículas ótimas (HU, s/d). Assim, por meio de uma simulação em um espaço bidimensional, um vetor define a posição da partícula e um outro estabelece o seu deslocamento (velocidade).

No caso do vetor de posição (Equação 1), as seguintes grandezas estão envolvidas (CARRILHO, 2007): momento da busca (k), quando está ocorrendo a varredura do espaço à procura de possíveis soluções; posição de cada partícula, em que será uma possível solução i no tempo $\mathrm{k}-\mathrm{p}_{\mathrm{k}}{ }^{\mathrm{i}}$ - define a posição em que cada possível solução possui no espaço de busca e posição da partícula i no tempo $\mathrm{k}+1-\mathrm{p}_{\mathrm{k}+1}^{\mathrm{i}}$.

$\mathrm{p}_{\mathrm{k}+1}^{\mathrm{i}}=\mathrm{p}_{\mathrm{k}}^{\mathrm{i}}+\mathrm{v}_{\mathrm{k}+1}^{\mathrm{i}}$

Por sua vez, no vetor de velocidade, as grandezas envolvidas (Equação 2) são: $\mathrm{k}-\mathrm{v}_{\mathrm{k}}^{\mathrm{i}}$ velocidade da partícula i no tempo; $\mathrm{v}_{\mathrm{k}+1}^{\mathrm{i}}$ - velocidade ajustada da partícula i no tempo $\mathrm{k}+1$; $\operatorname{rand}_{1}$ e rand $_{2}$ - números aleatórios independentes entre 0 e $1 ; \mathrm{C}_{1}$ - parâmetro cognitivo; $\mathrm{C}_{2}-$ parâmetro social; $\omega$ - fator de inércia (controla o impacto da velocidade prévia da partícula sobre sua velocidade atual); $\mathrm{k}$ - melhor posição do enxame no tempo (melhor posição alcançada por uma partícula usada para guiar as outras do enxame). $\mathrm{C}_{1}$ e $\mathrm{C}_{2}$ controlam o fluxo de 
informação entre a partícula e o seu enxame; quando $\mathrm{C}_{2}>\mathrm{C}_{1}$, há uma tendência de se aceitar o ponto ótimo global (gbest), caso contrário, encontra-se o ponto ótimo local $b_{k}{ }^{g}$.

$v_{\mathrm{k}+1}^{\mathrm{i}}=\omega v_{\mathrm{k}}^{\mathrm{i}}+\mathrm{C}_{1} \operatorname{rand}_{1}\left(\mathrm{~b}_{\mathrm{k}}^{\mathrm{i}}-\mathrm{p}_{\mathrm{k}}^{\mathrm{i}}\right)+\mathrm{C}_{2} \operatorname{rand}_{2}\left(\mathrm{~b}_{\mathrm{k}}^{\mathrm{g}}-\mathrm{p}_{\mathrm{k}}^{\mathrm{i}}\right)$

A componente cognitiva induz a partícula a explorar melhor a região próxima ao seu 'melhor individual' (pbest) ou onde ela, até o momento, encontrou um melhor resultado, com foco na busca em profundidade. Já a social direciona o movimento da partícula em direção ao "melhor da vizinhança" (lbest) ou ao ponto em que uma partícula próxima do enxame encontrou o melhor resultado (KENNEDY, 1997).

$\mathrm{Na}$ versão utilizada neste trabalho, a vizinhança é global (gbest), ou seja, há troca de informações entre todas as partículas, o que propicia que a convergência seja mais rápida do que quando a topologia local é utilizada.

$\mathrm{O}$ ajuste de tais componentes, representadas pelas constantes $\mathrm{C}_{1} \mathrm{e}$ $\mathrm{C}_{2}$, tem como objetivo equilibrar os dois processos de busca (largura e profundidade), conforme o problema a ser estudado.

Quanto maior for a componente social, mais rápida será a convergência. Entretanto, como esta velocidade aumenta, é possível que se passe por pontos ótimos sem que os mesmos sejam notados, prejudicando a análise do algoritmo (ENGELBRECHT, 2007).

Por outro lado, uma componente cognitiva com valores mais elevados, ou seja, acima de dois, permite que o algoritmo encontre um maior conjunto de soluções ótimas, sob um ponto de vista local, prejudicando, porém, a convergência para o ótimo global. Estudos acerca dessas componentes e sua influência no processo de convergência podem ser encontrados em Schutte e Groenwold (2005).

Considerando-se $\mathrm{C}_{1}=\mathrm{C}_{2}$, indica-se que o processo de convergência deve ocorrer prezando um equilíbrio entre as buscas em profundidade e largura, valorizando a convergência para um ótimo global, sem a perda da capacidade de exploração em profundidade.

Para o coeficiente de inércia $(\omega)$, Carrilho (2007) sugere o uso de valores entre 0 a 1,4. No entanto, Eberhart e Shi (2000) afirmam que o melhor comportamento dos algoritmos investigados ocorreu dentro da faixa de 0,4 a 0,9 .

Deve-se também limitar a velocidade máxima a fim de controlar o passo do algoritmo e prevenir o fenômeno de explosão, ou seja, evitar que a sua distância tenda para o infinito (TAYAL, 2003).

\section{METODOLOGIA}

A pesquisa desenvolvida contemplou duas etapas principais: elaboração da ferramenta de otimização e validação daquela proposta, por meio do desenvolvimento de um estudo de caso, considerando uma edificação existente representativa da categoria tarifária pública.

\section{Elaboração da ferramenta de otimização}

A ferramenta desenvolvida, denominada Rain Toolbox, contempla um módulo de simulação e um de otimização.

O módulo de simulação destina-se ao cálculo da evolução do VPL no tempo, em função de uma série histórica de precipitações e da estimativa dos futuros reajustes tarifários. Tem como saída o VPL final, que foi utilizado como função objetivo.

Já o de otimização abrange uma topologia global (gbest PSO), na qual a posição de uma partícula em um determinando instante representa um possível volume para o reservatório, a partir de um volume mínimo $\left(\mathrm{u}_{\min }\right)$, arbitrariamente estabelecido pelo usuário, e de um máximo $\left(\mathrm{u}_{\text {máx }}\right)$, determinado em função da definição da fração do lote que será ocupada para o seu posicionamento e de uma altura máxima preestabelecida.

Inicialmente, um enxame de dez partículas (número padrão, indicado na literatura) é criado e elas são dispostas uniformemente no espaço de busca, dentro do intervalo $\left[\mathrm{u}_{\min }, \mathrm{u}_{\max }\right]$. Em seguida, calcula-se o fitness de cada partícula e, a partir disso, cada uma atualiza a sua melhor posição pbest para a posição inicial, uma vez que elas conhecem apenas tal localização.

O gbest é definido como a posição da partícula com o melhor fitness do enxame. Nas iterações seguintes, as partículas atualizam a sua velocidade conforme a Equação 3:

$v_{i}(t+1)=v(t)+C_{1} r_{1}(t)\left[y_{i}(t)-x_{i}(t)\right]+C_{2} r_{2}(t)\left[\hat{y}(t)-x_{i}(t)\right]$

onde, $\mathrm{u}_{\mathrm{i}}(t)$ é a velocidade da partícula $i$ no instante $t ; \mathrm{x}_{\mathrm{i}}(t)$ é a posição da partícula $i$ no instante $t$; $c_{1}$ e $c_{2}$ são constantes de aceleração que representam as componentes cognitiva e social do aprendizado; $r_{1}(t)$ e $\mathrm{r}_{2}(t)$ são valores aleatórios, amostrados a partir de uma distribuição uniforme $\mathrm{U}(0,1)$.

As componentes cognitivas e sociais $c_{1}$ e $c_{2}$ foram definidas neste trabalho como semelhantes a dois. Este valor foi obtido empiricamente, produzindo um equilíbrio satisfatório entre a capacidade de realizar buscas em profundidade e amplitude. Contudo, é possível alterá-lo na ferramenta desenvolvida e verificar o impacto produzido.

A melhor posição que uma partícula $i$ encontra até então, ou seja, o pbest, é representada por $\mathrm{y}_{\mathrm{t}}$, sendo o cálculo do pbest efetuado a partir da Equação 4:

$y_{i}(t)=y_{i}(t)$ se $f\left(x_{i}(t+1)\right) \leq f\left(y_{i}(t)\right)$

$x_{i}(t+1)$ se $f\left(x_{i}(t+1)\right)>f\left(y_{i}(t)\right)$

onde, $\mathrm{f}: \mathrm{R} \rightarrow \mathrm{R}$ (domínio da função em números reais) é a função de fitness, representada pelo VPL em função do volume do reservatório. 
Se, em um dado instante $t$, uma partícula $x$ encontra uma posição correspondente ao volume que produz um VPL melhor do que o melhor encontrado por ela até então, o pbest será atualizado para a posição que tal partícula ocupa no instante $t$.

Assim, a partir dos passos apresentados, mensura-se o volume que representa o maior VPL.

\section{Aplicação da ferramenta de otimização proposta}

A fim de demonstrar a utilização da ferramenta proposta, foram construídos cenários de investimento em um sistema predial de aproveitamento de água pluvial para uma edificação pública, conforme descrito na sequência.

Como investimento inicial, foi considerado o custo de construção do reservatório (mão de obra e material). As demais despesas foram desprezadas nesta análise porque são muito similares para diferentes volumes de reserva. No entanto, tais custos podem ser considerados em outras aplicações, pois a forma de entrada dos dados permite que se agreguem outros itens ao investimento inicial.

Assim, para a construção da função do custo, dado de entrada do programa computacional desenvolvido, foram considerados os valores correspondentes à execução de reservatórios com diferentes volumes, aplicados por uma construtora de médio porte que atua na cidade de Campinas, São Paulo, Brasil. A função ajustada, com coeficiente de determinação, $\mathrm{R}^{2}$, igual a 0,99, é apresentada na Equação 5:

$\mathrm{C}=0,2404 \mathrm{~V}^{1,0988}$

onde, C é o custo do reservatório, em reais, e V é o volume do reservatório, em L.

As entradas e saídas consideradas no fluxo de caixa para a determinação do VPL do estudo de caso são:

- entradas: economias, em termos mensais, geradas pelo consumo de água pluvial na edificação;

- saídas: custos de manutenção (mensais, bimestrais, semestrais e anuais).

\section{Entradas do fluxo de caixa - economias mensais}

Os valores da conta de água, considerando-se que parte da demanda será atendida com água não potável, constituem-se nas entradas do fluxo de caixa para a determinação do VPL.

Os volumes de água pluvial que serão utilizados em substituição à potável são determinados diariamente, a partir da Equação 6:

$\mathrm{V}_{\mathrm{t}}=\mathrm{V}_{\mathrm{t}-1}+\mathrm{V}_{\mathrm{aprov}}-\mathrm{D}$

onde, $\mathrm{V}_{\mathrm{t}}$ é o volume existente no reservatório no final do dia, $\mathrm{em} \mathrm{m}^{3} ; \mathrm{V}_{\mathrm{t}-1}$ é o volume inicial do reservatório, $\mathrm{em} \mathrm{m}^{3} ; \mathrm{V}_{\text {aprov }}$ é o volume aproveitado (Equação 7), em $\mathrm{m}^{3}$ e D é a demanda diária de água pluvial, em $\mathrm{m}^{3}$.
Para a estimativa da oferta de água pluvial, foram considerados os dados de precipitação registrados no posto pluviométrico de Barão Geraldo, localizado na cidade de Campinas, São Paulo, para um período de 38 anos (1971 a 2009), os quais são disponibilizados em Agritempo (s/d).

Do histórico de precipitações e da área de captação, a oferta de água pluvial foi estimada a partir da Equação 7 (ABNT, 2007):

$\mathrm{V}_{\text {aprov }}=\mathrm{p} \mathrm{A} \eta$

onde, $\mathrm{V}_{\text {aprov }}$ é o volume de água pluvial aproveitável (oferta de água pluvial), em $\mathrm{m}^{3}$; p é a precipitação diária, em m; A é a área de coleta, em $\mathrm{m}^{2}$ e $\eta$ é o coeficiente de aproveitamento, adimensional.

Para a determinação dos valores da conta de água, considerou-se a estrutura tarifária aplicada pela concessionária de água e esgoto local, conforme a Tabela 1.

A simulação inicial não considera reajustes futuros das tarifas de água e esgoto. Para ilustrar o emprego da ferramenta proposta em análises de sensibilidade, dois outros cenários foram considerados, os quais correspondem aos limites inferior e superior dos reajustes históricos aplicados pela concessionária local entre 2001 e 2009: 5,59 e 19,63\% (SANASA, s/d). É importante destacar que tais valores são apenas ilustrativos, uma vez que não expurgam os efeitos inflacionários. Para cada um desses cenários foram consideradas duas situações: com e sem a cobrança da tarifa de esgoto sanitário equivalente ao volume de água pluvial utilizado, correspondente a $100 \%$ da água consumida.

Portanto, foram considerados para o estudo de caso em questão três cenários, cada um deles com e sem a cobrança da tarifa de esgoto decorrente do uso da água pluvial: estrutura tarifária conforme a Tabela 1; tarifa com reajuste de 5,59\% e outra com $19,63 \%$.

\section{Saídas do fluxo de caixa - custos de operação e manutenção}

Os custos de operação e manutenção são informados em termos de sua periodicidade (mensal, bimensal, semestral ou anual). A Tabela 2 apresenta os custos de operação e manutenção considerados no estudo de caso desenvolvido neste trabalho. Atentou-se para o fato que o

Tabela 1 - Tarifa dos serviços de abastecimento de água aplicadas pela concessionária de água e esgoto da cidade de Campinas - SANASA, para a categoria pública (ano-base: 2011).

\begin{tabular}{l|c}
\hline Faixa de consumo $\left(\mathrm{m}^{3} \cdot\right.$ mês $\left.^{-1}\right)$ & Valor da conta $(\mathrm{R} \$)$ \\
\hline O a 10 & 21,53 \\
\hline 11 a 20 & $6,08 \mathrm{~V}-39,27$ \\
\hline 21 a 40 & $10,12 \mathrm{~V}-120,07$ \\
\hline 41 a 50 & $12,14 \mathrm{~V}-200,87$ \\
\hline Acima de 50 & $15,83 \mathrm{~V}-385,37$ \\
\hline
\end{tabular}

Fonte: SANASA (s/d). 
esvaziamento do reservatório para a limpeza seria efetuado no período de chuva, mais especificamente em janeiro, quando existe um extravasamento, porque a oferta supera a demanda, não acarretando, portanto, custos adicionais.

\section{Taxa de atratividade e duração do projeto}

A taxa de atratividade é a quantidade de juros que representa o que o investidor se propõe a ganhar quando decide fazer um investimento. É composta pelo custo de oportunidade, o risco do negócio a ser feito e a liquidez do empreendimento. Segundo Lima Jr. et al. (2011, p. 439), "a taxa de atratividade deve ser imposta por quem compra o empreendimento, pois o comprador é quem vai assumir o risco de investir".

Considerando a similaridade com os estudos desenvolvidos por Lima Jr. e Alencar (2006) e Alencar (2004), a qual é traduzida por longos períodos dos projetos investigados e grande incerteza dos valores econômicos a serem praticados no futuro, selecionou-se, neste trabalho, uma taxa de atratividade de $9 \%$ a.a.

A duração do projeto, por sua vez, pode ser definida como o período do investimento em que haverá entradas e saídas do fluxo de caixa. Durante este tempo, o projeto estará economicamente produtivo. No presente trabalho, a duração do projeto equivaleu à vida útil do reservatório, ou seja, 20 anos, conforme a Associação Brasileira de Normas Técnicas - ABNT (2010).

Tabela 2 - Despesas consideradas para a determinação do valor presente líquido.

\begin{tabular}{|c|c|c|c|}
\hline Descrição & Periodicidade & Critérios & Valor ${ }^{\mathrm{a}}$ \\
\hline $\begin{array}{l}\text { Consumo de } \\
\text { energia }\end{array}$ & \multirow{5}{*}{ Mensal } & $\begin{array}{c}\text { Conjunto } \\
\text { moto-bomba } \\
\text { funcionando } \\
10 \text { h.dia- }^{-1}\end{array}$ & $\mathrm{R} \$ 22,2 \mathrm{O}$, por mês \\
\hline $\begin{array}{l}\text { Consumo do } \\
\text { produto de } \\
\text { desinfecção }\end{array}$ & & $\begin{array}{c}4 \mathrm{~g} \text { para cada } \\
\text { 1.000 L de águab } \\
\text { balde de } 1 \mathrm{~kg} \text { de } \\
\text { cloro }\end{array}$ & $\begin{array}{l}\mathrm{R} \$ 0,08 \text { por } \mathrm{m}^{3}, \\
\text { por mês }\end{array}$ \\
\hline \multirow{3}{*}{$\begin{array}{l}\text { Realização de } \\
\text { ensaios previstos } \\
\text { pela ABNT (2007) }\end{array}$} & & $\begin{array}{l}\text { Parâmetros: cloro } \\
\text { (fitas) e pH }\end{array}$ & $\begin{array}{c}\text { Pacote com } 50 \\
\text { fitas: } \mathrm{R} \$ 36,00 \text {, } \\
\text { no que resulta } \\
\mathrm{R} \$ 0,72 \text {, por mês }{ }^{c}\end{array}$ \\
\hline & & Turbidez & $\mathrm{R} \$ 12,00$, por mêsc \\
\hline & & Cor & $\mathrm{R} \$ 12,00$, por mês ${ }^{c}$ \\
\hline \multicolumn{4}{|c|}{ Custo ( $R \$ / m e ̂ s): 0,08 \mathrm{~V}+46,92$, onde $V$ é o volume do reservatório $\left(\mathrm{m}^{3}\right)$} \\
\hline Limpeza do filtro & Bimestral & $\begin{array}{c}\text { Mão de obra para } \\
\text { realizar o serviço } \\
\text { (meia diária de } \\
\text { um servente) }\end{array}$ & $\begin{array}{c}\mathrm{R} \$ 31,2 \mathrm{O} \text {, por } \\
\text { bimestre }^{\mathrm{d}}\end{array}$ \\
\hline $\begin{array}{l}\text { Realização de } \\
\text { ensaios previstos } \\
\text { pela ABNT (2007) }\end{array}$ & Semestral & $\begin{array}{c}\text { Parâmetros: } \\
\text { coliformes totais } \\
\text { e termotolerantes }\end{array}$ & $\begin{array}{l}\text { R\$90,00, por } \\
\text { semestre }^{c}\end{array}$ \\
\hline $\begin{array}{l}\text { Manutenção em } \\
\text { geral (limpeza } \\
\text { do reservatório, } \\
\text { bomba) }\end{array}$ & Anual & $\begin{array}{l}\text { Mão de obra para } \\
\text { realizar o serviço } \\
\text { (diária de um } \\
\text { servente) }\end{array}$ & $\begin{array}{l}\mathrm{R} \$ \text { 62,40, por } \\
\mathrm{ano}^{\mathrm{d}}\end{array}$ \\
\hline
\end{tabular}

adata-base: setembro de 2011; bFUNASA (2001); ‘CQA (2011); ‘SINTRACONSP (2011).

\section{RESULTADOS E DISCUSSÃO}

O algoritmo do programa de otimização desenvolvido está apresentado na Figura 1.

A interface gráfica da parte de otimização do projeto desenvolvido demonstra cinco módulos para entrada de dados.

No primeiro módulo, devem ser informados a área do lote; a área de captação da água pluvial na edificação; a taxa de ocupação do lote para o posicionamento do reservatório e o coeficiente de aproveitamento. Já no segundo, deve-se inserir o material do reservatório a ser dimensionado - por enquanto, apenas dois materiais estão contemplados no programa desenvolvido, concreto armado e fibra de vidro; a categoria tarifária - atualmente, o programa contém apenas as categorias e estruturas tarifárias da cidade de Campinas, São Paulo; a demanda diária de água pluvial, que deve ser inserida por meio de um arquivo no formato csv (comma-separated values), referente a 365 dias, e a altura máxima permitida para o reservatório.

O módulo três contempla a inserção dos dados relativos às funções dos custos do reservatório e de manutenção e operação. Foi considerado inicialmente apenas o custo do reservatório, o qual representa a maior parte dos investimentos necessários (YRUSKA et al., 2010), contudo, podem ser incorporados futuramente outras despesas. Isso se deve ao fato de que o restante do sistema de água pluvial tem que ser previsto independentemente do aproveitamento. Além disso, o volume armazenado, confrontado com a oferta de água pluvial, é o que determinará a parcela da demanda dessa fonte alternativa que poderá ser efetivamente utilizada e o quanto de retorno econômico, em termos de redução dos gastos com o uso da água potável, o sistema oferecerá.

No módulo quatro, deve-se inserir o histórico de precipitações diárias, bem como o de reajustes da tarifa, ambos em arquivo no formato csv.

Por fim, no módulo cinco, devem ser colocados os dados referentes à otimização PSO: número de partículas e iterações. Além disso, deve ser informado o volume mínimo para o início das simulações.

\section{Aplicação da ferramenta de otimização - estudo de caso}

A demanda diária de água pluvial da edificação em estudo foi estimada conforme a Tabela 3. A área de captação corresponde à da cobertura, conforme ABNT (2007), ou seja, $1.222 \mathrm{~m}^{2}$. Tal procura é variável em função dos dias da semana e também ao longo dos meses do ano, sendo o valor mínimo igual a 0,764 e o máximo, $2,522 \mathrm{~m}^{3} \cdot \mathrm{dia}^{-1}$.

Destaca-se que o regime pluviométrico do local em estudo é caracterizado por uma estação chuvosa (de setembro a março); nos demais meses, a oferta de água pluvial é inexistente ou mínima, resultando em uma diminuição dos retornos econômicos nesses períodos.

A Tabela 4 apresenta os volumes e respectivos VPL para os três cenários descritos anteriormente, considerando-se um período de 20 anos. 


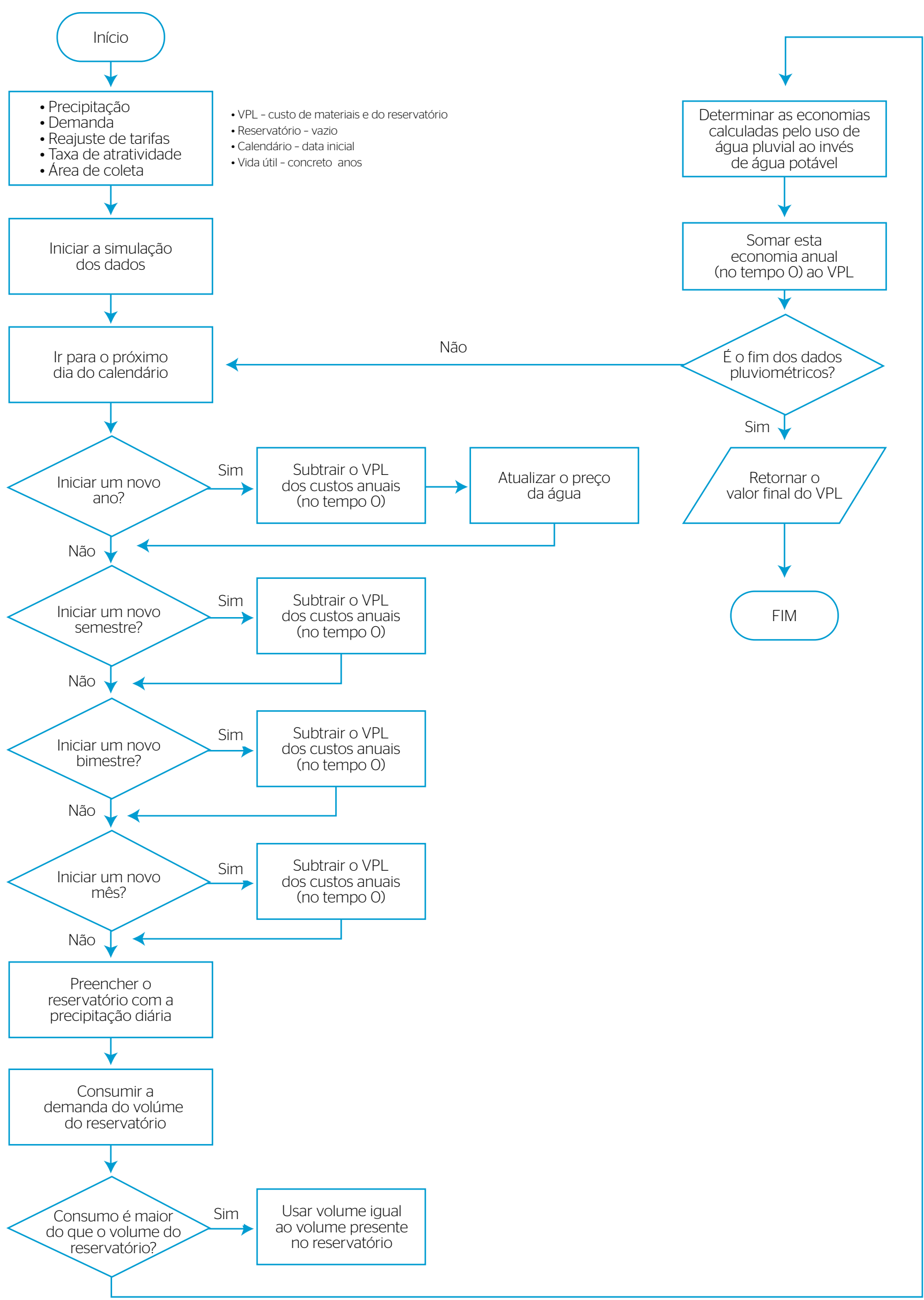

E: entrada mensal - proveniente da economia na conta de água; i: tarifa de reajuste; VPL: valor presente líquido.

Figura 1 - Fluxograma empregado para a determinação do valor presente líquido no desenvolvimento do estudo de caso. 
Verifica-se que o exercício de cenários com reajustes mais elevados promove oportunidade para o emprego de maiores volumes, uma vez que permite ter retornos econômicos maiores para equilibrar e ultrapassar os investimentos em tais reservatórios, melhorando a qualidade do investimento na medida em que se aumenta a tarifa. Desse modo, o volume de água potável que seria substituído compensaria os investimentos no sistema de aproveitamento de água pluvial a ser construído. Sendo assim, mesmo tendo que pagar esta taxa, torna-se mais viável para o investidor substituir um maior volume de água potável, pois essa "maior reserva" aumenta a oportunidade de retornos econômicos, reduzindo a possibilidade de perdas.

Este comportamento ficou bastante evidente no caso em que se aplicou a tarifa de esgoto correspondente ao uso da água. Também observou-se quando essa taxa não foi incluída, entretanto a magnitude do aumento do volume é menor do que quando a mesma foi considerada. Isso se deve ao fato de que o retorno econômico, quando da inexistência da tarifa de esgoto, é menor, e, portanto, não há vantagem econômica em se adotar um volume maior de armazenamento.

Por exemplo, comparando-se o cenário C (reajuste anual de 19,63\%) com o A (sem reajuste), nota-se um aumento do volume de aproximadamente $270 \%$ no caso da cobrança da tarifa de esgoto e de cerca de $107 \%$ quando da inexistência da referida taxa.

Efetuou-se também uma análise de sensibilidade empregando a ferramenta desenvolvida e considerando diferentes volumes teóricos dentro dos cenários de estrutura tarifária apresentados, com o intuito de validar o resultado obtido com o emprego da PSO ao determinar o maior VPL possível. A Figura 2 apresenta os resultados obtidos, respectivamente, para os cenários que consideram a cobrança do esgoto gerado pelo uso da água pluvial e aqueles que desconsideram a referida tarifa.

Para todas as estruturas tarifárias e os cenários de cobrança da taxa de esgoto, os valores obtidos pela PSO coincidem com os máximos atingidos pela simulação. Esses resultados permitem também, caso desejado, a escolha de um volume que não seja necessariamente o ótimo do ponto de vista econômico, caso os investimentos iniciais necessários para implantá-lo não estejam disponíveis. Além disso, é possível avaliar o montante de recursos econômicos que seriam investidos de forma desnecessária com volumes maiores do que o ótimo sob este ponto de vista, contribuindo diretamente para a qualidade do investimento realizado.

\section{Validação das variáveis do algoritmo da Particle Swarm Optimization - análise de sensibilidade}

Para a validação do algoritmo da PSO proposto, foram avaliados os efeitos da variação dos parâmetros cognitivos, de forma que $\mathrm{C}_{1}+\mathrm{C}_{2}=4$ e do fator de inércia $\omega$ entre 0,4 e 0,9 , conforme a literatura consultada. Assim, as seguintes combinações de valores foram analisadas, considerando-se não somente a classe tarifária pública, mas também a comercial e a industrial: parâmetros cognitivos e sociais: $\mathrm{C}_{1}=\mathrm{C}_{2}=2 ; \mathrm{C}_{1}=1,5$ e $\mathrm{C}_{2}=2,5 ; \mathrm{C}_{1}=2,5$ e $\mathrm{C}_{2}=1,5 ; \mathrm{C}_{1}=3$ e $\mathrm{C}_{2}=1$; $\mathrm{C}_{1}=1$ e $\mathrm{C}_{2}=3$; fatores de inércia: $0,5,0,6$ e 0,8 .

Os resultados foram similares para diferentes $\mathrm{C}_{1}$ e $\mathrm{C}_{2}$ em todas as classes tarifárias consideradas. Por sua vez, a variação do fator de inércia resultou em flutuações do valor do volume representativo do maior VPL em torno de 0,01 a $0,02 \mathrm{~m}^{3}$, que podem ser consideradas desprezíveis em função da magnitude dos volumes totais de armazenamento alcançados.

Tais dados corroboram com aqueles constantes em estudos que empregam a PSO no desenvolvimento de ferramentas de otimização consultados na literatura. Em determinados problemas, com universos pequenos, os fatores analisados têm pouca ou nenhuma variação quando usados dentro das faixas consideradas (EBEHART \& SHI, 2000; SCHUTTE \& GROENWOLD, 2005; ENGELBRECHT, 2007).

Tabela 4 - Volumes e respectivos valores máximos do VPL, considerando a tarifa de água e esgoto sem reajuste nos próximos 20 anos (A), com reajuste anual de 5,59\% (B) e com reajuste anual de $19,63 \%$ (C) edificação pública.

\begin{tabular}{l|c|c|c|c}
\multirow{2}{*}{$\begin{array}{l}\text { Cenário de } \\
\text { valor da } \\
\text { conta }\end{array}$} & \multicolumn{2}{|c|}{$\begin{array}{c}\text { Com cobrança da taxa de esgoto } \\
(100 \% \text { do consumo de água) }\end{array}$} & $\begin{array}{c}\text { Sem cobrança da taxa } \\
\text { de esgoto }\end{array}$ \\
\cline { 2 - 5 } & Volume $\left(\mathrm{m}^{3}\right)$ & VPL (R\$) & Volume $\left(\mathrm{m}^{3}\right)$ & VPL (R\$) \\
\hline A & 14,96 & $59.845,21$ & 15,21 & $20.287,02$ \\
\hline B & 18,76 & $104.293,30$ & 16,52 & $41.435,38$ \\
\hline C & 55,38 & $485.449,30$ & 31,49 & $231.990,50$ \\
\hline
\end{tabular}

Tabela 3 - Estimativa da demanda de água pluvial - edificação existente, representativa da categoria tarifária pública.

\begin{tabular}{|c|c|c|}
\hline Caracterização da edificação & População & Dados para a estimativa da demanda diária de água pluvial \\
\hline $\begin{array}{l}\text { - Conjunto de edifícios } \\
\text { de salas de aula de } \\
\text { uma instituição de } \\
\text { ensino superior; com } \\
\text { um pavimento térreo } \\
\text { e três pavimentos-tipo, } \\
\text { totalizando oito banheiros. } \\
\text { - Área de jardim: } 30 \text { m²; área } \\
\text { de piso lavável: } 1.527 \text { m². }\end{array}$ & $\begin{array}{l}\text { - Flutuante: média } \\
\text { semanal de } 2.405 \\
\text { alunos, } 441 \text { usuários } \\
\text { por dia útil e } 200 \\
\text { aos sábados; fixa: } \\
11 \text { pessoas. }\end{array}$ & $\begin{array}{l}\text { - Número médio de acionamentos da descarga das bacias sanitáriasa nos dias da semana } \\
\text { e aos sábados: 0,9 descarga por aluno por dia; 75\% delas com volume parcial (3,4 L por } \\
\text { - } \text { lescarga) e 25\% com total (6,8 L por descarga). } \\
\text { - uma vazão paisagísticaa: três vezes por semana (às segundas, quintas e aos sábados, com } \\
\text { - Lavagem do piso: (a) a com pano e balde durantes os dias úteis, utilizando } 0,5 \text { L por m² e } \\
\text { (b) a com balde e rodo aos sábados, utilizando 1,0 L por m². } \\
\text { - Variação sazonal: irrigação do jardim e lavagem do piso ao longo do ano, } \\
\text { independentemente das férias escolares; uso da bacia sanitária somente de março a junho, } \\
\text { na primeira quinzena de julho, agosto a novembro e nos últimos dez dias de dezembro. }\end{array}$ \\
\hline
\end{tabular}

alevantados via questionário ou medidos no local; ' Melo, Neto (1988) apud Tomaz (2000). 
A

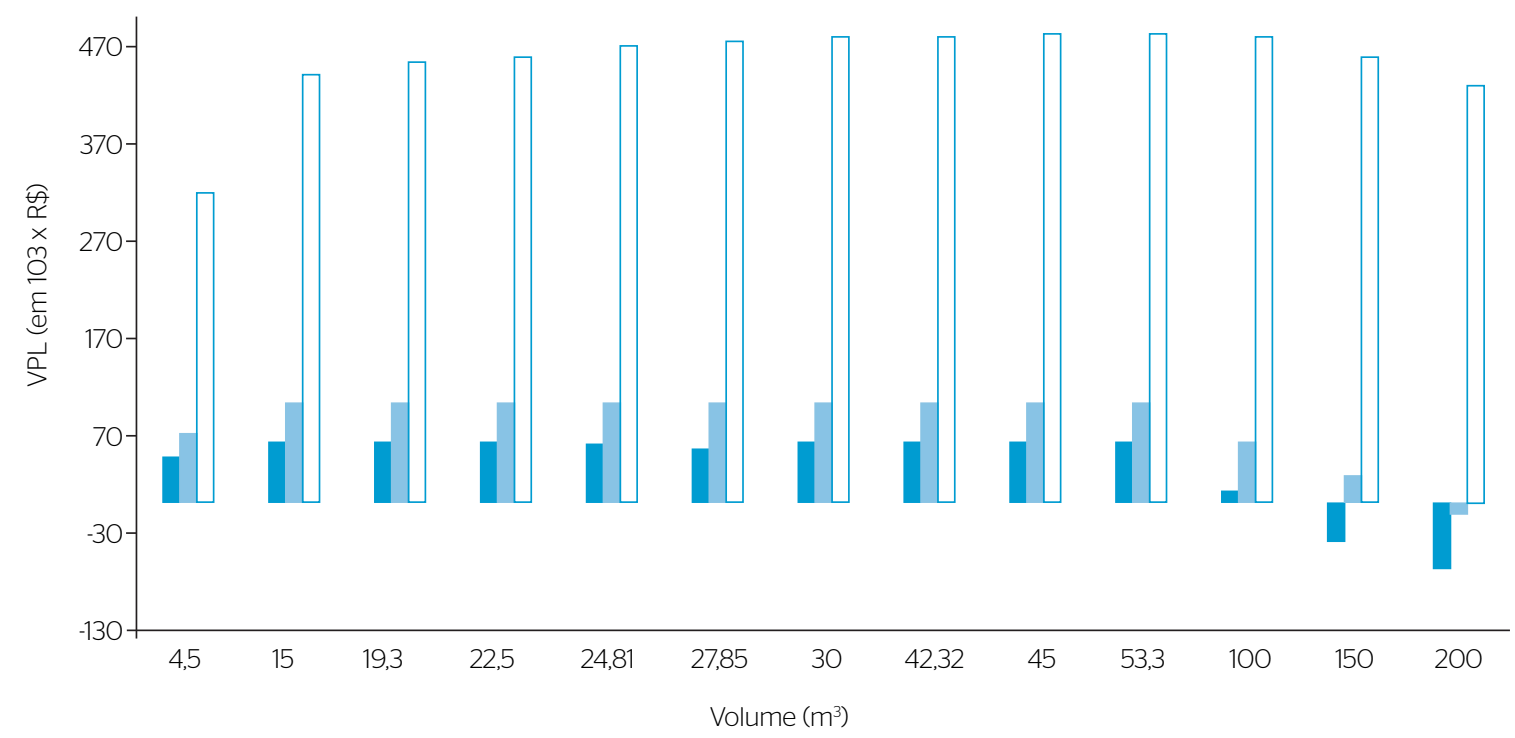

B

sem reajuste $\square$ reajuste anual de 5,59\% $\square$ reajuste anual de 19,63\%

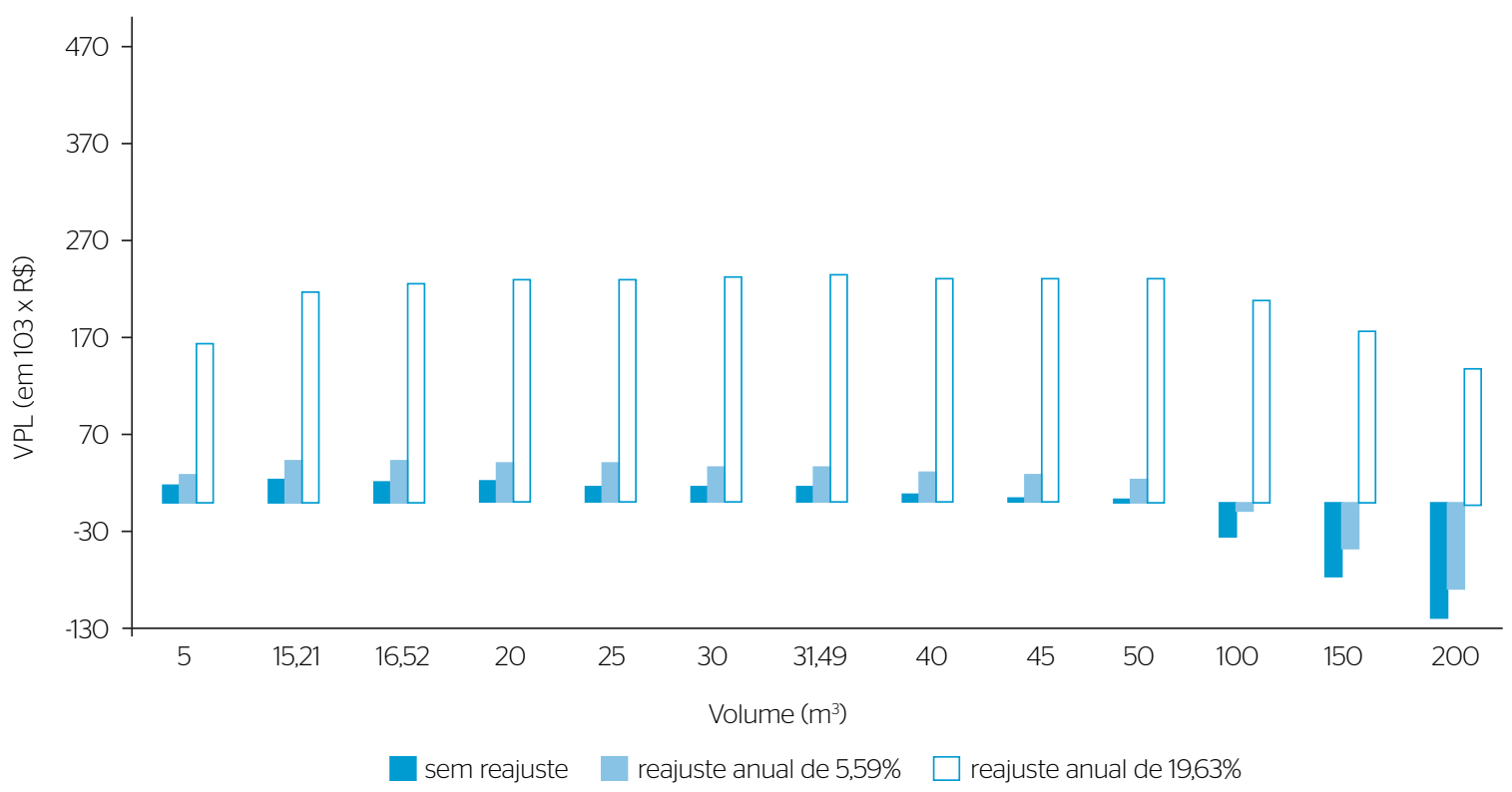

VPL: valor presente líquido.

Figura 2 - Valores de valor presente líquido correspondentes a diversos volumes de armazenamento, considerando a estrutura tarifária atual: (A) com a cobrança da tarifa de esgoto correspondente ao uso da água pluvial e (B) sem a cobrança da tarifa de esgoto e para os cenários considerados: sem reajuste e com reajustes de 5,59 e 19,63\% ao ano.

\section{CONCLUSÕES}

Este trabalho propôs uma ferramenta que permite a análise da qualidade de investimentos na tomada de decisões da implantação dos sistemas de aproveitamento de água pluvial, a qual é baseada na otimização do VPL, por meio da técnica PSO.

Em sua aplicação, de modo a evidenciar a sua flexibilidade, foi considerada uma edificação da categoria pública e três cenários para a tarifa: valor sem reajustes, reajuste mínimo histórico (5,59\% ao ano) e reajuste máximo histórico (19,63\% ao ano), todos sem e com a cobrança da tarifa de esgoto decorrente do uso de água pluvial.

Há que se considerar também que, se, por um lado, as tarifas de água e esgoto possam ser muito mais elevadas, por outro, a existência de uma política de subsídios públicos, como a que se tem no presente, pode distorcer a estrutura tarifária a ser empregada no futuro. A parcela que é efetivamente subsidiada, por quanto tempo este subsídio existirá 
e qual o valor que ela representará são informações importantes para a análise da qualidade dos investimentos; contudo, não há domínio dessas informações por parte dos investidores.

Além disso, dois outros fatores podem contribuir para um maior aumento da tarifa, tornando o investimento em sistemas de aproveitamento de água pluvial mais vantajoso do ponto de vista econômico: a cobrança pelo uso da água bruta, já implantada em algumas bacias hidrográficas do país, cujos custos poderão ser repassados para os usuários finais e a cobrança de tarifa de drenagem. Nesse sentido, ressalta-se que a Lei Federal 9.433, no Artigo 12 (BRASIL, 1997), permite a cobrança pelo lançamento de esgoto pluvial em corpos hídricos. Embora amparada sob aspectos legais e técnicos, inclusive com jurisprudência de julgamento do Superior Tribunal Federal, esta tarifa ainda não existe na maioria dos municípios brasileiros. Entretanto, há grande possibilidade que esta previsão se torne realidade nos próximos anos, devido à crescente necessidade de investimentos para o controle das cheias urbanas.

No estudo de caso desenvolvido, verificou-se que a cobrança da tarifa de esgoto decorrente do uso da água pluvial não diminuiu a atratividade do investimento no sistema de aproveitamento de água pluvial, ou seja, mesmo tendo que pagar esta tarifa, houve aumento da oportunidade de retorno econômico, reduzindo a possibilidade de perdas.

O modelo desenvolvido e apresentado neste artigo está restrito à estrutura tarifária de uma concessionária, bem como à cobrança de $100 \%$ da tarifa de água para contabilizar aquela de esgoto. No entanto, tais restrições podem ser modificadas no algoritmo original, como inclusive foi feito para retirar a cobrança da tarifa de esgoto no estudo de caso desenvolvido.

Outras restrições, as quais dependem do local em estudo, tais como custos de materiais e operação/manutenção, índices pluviométricos e histórico de reajustes tarifários, são dados de entrada do sistema e podem ser, portanto, adaptadas a outras situações de projeto.

Tendo em vista o exposto, destaca-se que os resultados obtidos neste trabalho, com a aplicação da ferramenta proposta, são apenas ilustrativos e não devem ser generalizados para regimes pluviométricos, estruturas tarifárias e materiais de construção diferenciados dos utilizados nas simulações efetuadas. Além disso, a demanda de água pluvial foi estimada para o caso em questão e pode ser diferenciada para outras realidades de consumo.

\section{REFERÊNCIAS}

AGRITEMPO. (s/d) Sistema de monitoramento agrometeorógico. Disponível em: <http://www.agritempo.gov.br>. Acesso em: 23 set. 2010 .

ALENCAR, C.T. (2004) O equilíbrio entre a sustentabilidade e a atratividade do investimento em edifícios de escritórios para locação em São Paulo. In: Conferência Latino-americana de Construção Sustentável, Encontro Nacional de Tecnologia do Ambiente Construído. São Paulo. Anais eletrônicos... São Paulo.

AMORIM, S.V. \& PEREIRA, D.J.A. (2008) Estudo comparativo dos métodos de dimensionamento para reservatórios utilizados em aproveitamento de água pluvial. Ambiente Construído, v. 8, p. 53-66.

ASSOCIAÇÃO BRASILEIRA DE NORMAS TÉCNICAS. (2007) NBR 15527: água de chuva - Aproveitamento de coberturas em áreas urbanas para fins não potáveis - Requisitos. Rio de Janeiro.

ASSOCIAÇÃO BRASILEIRA DE NORMAS TÉCNICAS. (2010) NBR 15575: Edifícios habitacionais de até cinco pavimentos - Desempenho Parte 1; Requisitos Gerais. Rio de Janeiro.

BOERINGER, D.W. \& WERNER, D.H. (2004) Particle Swarm Optimization Versus Genetic Algorithms for Phased Array Synthesis. IEEE Transactions on Antennas and Propagation, v. 52, n. 3.

BRASIL. (1997) Lei no 9.433, de 8 de janeiro de 1997. Institui a Política Nacional de Recursos Hídricos, cria o Sistema Nacional de Recursos Hídricos, regulamenta o inciso XIX do art. 21 da Constituição Federal, e altera o art. 10 da Lei no 8.001, de 13 de março de 1990, que modificou a Lei no 7.990, de 28 de dezembro de 1989. Diário Oficial da República
Federativa do Brasil, Brasília, DF, n. 6, 09 de janeiro de 1997, Seção 1, p. $470-474$

CAMPOS, M.A.S. (2004) Aproveitamento de água pluvial em edifícios residenciais multifamiliares na cidade de São Carlos. Dissertação (Mestrado) - PPGCiv/DECiv, UFSCar, São Carlos, 131 p.

CANÔAS, A.C.G. (2008) Lógica nebulosa e técnica de otimização particle swarm aplicadas ao controle de tensão e de potência reativa. Tese (Doutorado) - FEEC-Unicamp, Campinas, 139 p.

CARRILHO, O.J.B. (2007) Algoritmo híbrido para avaliação da integridade estrutural: uma abordagem heurística. Tese (Doutorado) EESC-USP, São Carlos, 162 p.

CENTRO DE QUALIDADE ANALITICA - CQA. (2011) Disponível em: <http://www.cqa.com.br>. Acesso em: 30 set. 2011.

EBERHART, R.C. \& SHI, Y. (2000) Comparing inertia weights and constriction factors in particle swarm optimization. [S.I.]: IEEE.

ENGELBRECHT, A.P. (2007) Computational intelligence: an introduction 2 ed. Nova lorque: Wiley. 630 p.

FUNDAÇÃO NACIONAL DE SAÚDE - FUNASA. (2001) Portaria N. 1.469Controle e Vigilância da Qualidade da Água para Consumo Humano e seu Padrão de Potabilidade. Brasília. Disponível em: <http://portal.saude gov.br/portal /arquivos/ pdf/ portaria1469.pdf>. Acesso em: 31 jan. 2012.

HU, X. (s/d) Particle Swarm Optimization. Disponível em: <http://www swarmintelligence.org>. Acesso 13 nov. 2009. 
KENNEDY, J. (1997) The particle swarm: social adaptation of knowledge. In: IEEE International Conference on Evolutionary Computation. [S.I: s.n.].

LIMA, J.A.; DAMBROS, M.V.R; ANTONIO, M.A.P.M.; JANZEN, J.G.; MARCHETTO, M. (2011) Potencial da economia de água potável pelo uso de água pluvial: análise de 40 cidades da Amazônia. Revista de Engenharia Sanitária e Ambiental, Rio de Janeiro, v. 16, n. 3, p. 291-298

LIMA JR, J.R. \& ALENCAR, C.T. (2006) The office buildings market in São Paulo: time cycles to absorb vacant space and to recover investment attractiveness. Journal of Financial Management, v. 11, n. 1, p. 171-180.

LIMA JR, J.R.; MONETTI, E.; ALENCAR, C.T. (2011) Real Estate: fundamentos para análise de investimentos. Rio de Janeiro: Elsevier. 456 p.

MAY, S. (2004) Estudo de viabilidade do aproveitamento de água de chuva para consumo não potável em edificações. Dissertação (Mestrado) - EPUSP-USP, São Paulo, 159 p.

MONTEIRO, R.C. (2003) Contribuições da abordagem de avaliação de opções reais em ambientes econômicos de grande volatilidade - uma ênfase no cenário latino-americano. Dissertação (Mestrado) - FEA-USP, São Paulo, 200 p.

SANASA. (s/d) Resolução Tarifária 01/2011. Disponível em: <http://www. sanasa.com.br>. Acesso em: 21 jan. 2012.

SCHUTTE, J.F. \& GROENWOLD, A.A. (2005) A study of global optimization using particle swarms. Journal of Global Optimization, v. 31, n. 1, p. 93-108.
SINDICADO DOS TRABALHADORES NAS INDÚSTRIAS DA CONSTRUÇÃO CIVIL DE SÃO PAULO - SINTRACONSP. (2011) Convenção Coletiva de Trabalho. Ano 2011, São Paulo. Disponível em: <http://www.sintraconsp.org.br>. Acesso em: 30 jan. 2012.

TAYAL, M. (2003) Particle Swarm Optimization for Mechanical Design. Dissertação (Mestrado) - Universidade de Texas, Arlington, Texas, Estados Unidos, 93 p.

TOMAZ, P. (2000) Previsão de consumo de água. 1 ed. Rio de Janeiro: Navegar. $250 \mathrm{p}$.

VANHOUCKE, M. (2009) A genetic algorithm for Net Present Value Maximization for resource constrained projects. In: Nineth European Conference on Evolutionary Computation in Combinatorial Optimization. Germany, Tübingen.

YRUSKA, I.; BRAGA, L.G.; SANTOS, C.A.G. (2O10) Viability of precipitation frequency use for reservoir sizing in Condominiums. Journal of Urban and Environmental Engineering, v. 4, n. 1, p. 23-28.

YWASHIMA, L.A. (2005) Avaliação do uso de água em edifícios escolares públicos e análise de viabilidade econômica da instalação de tecnologias economizadoras nos pontos de consumo Dissertação (Mestrado) - FEC-UNICAMP, Campinas, 312 p.

ZANG, H. \& WANG, J.Y. (2008) Particle swarm optimization for construction site unequal-area layout. Journal of Construction Engineering and Management, v. 134, n. 9, p. 739-748. 